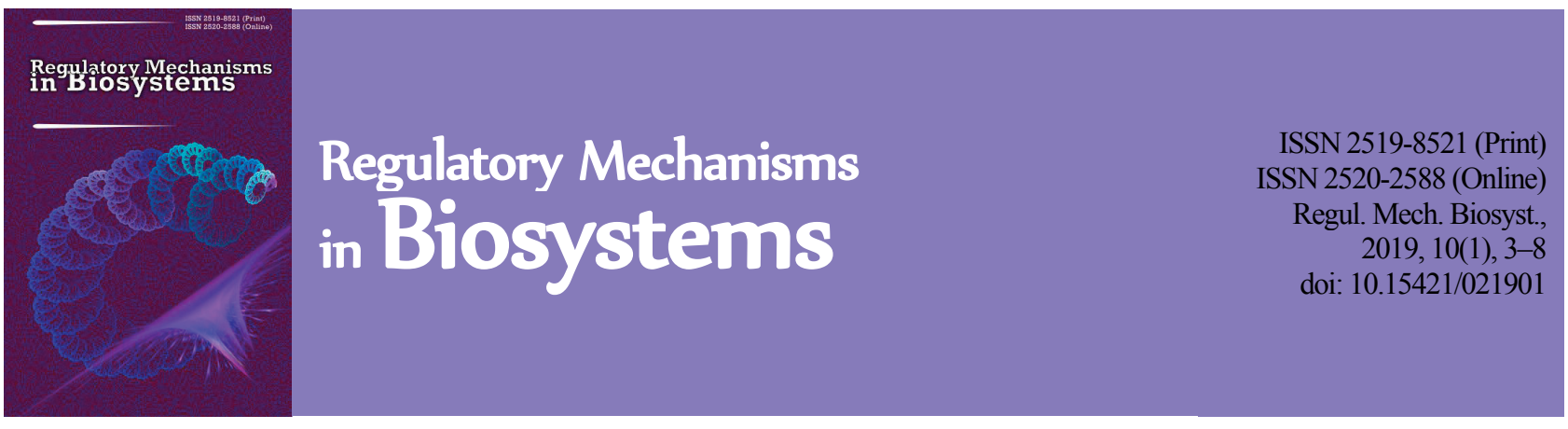

\title{
Effect of disintegrates and metabolites of Lactobacillus rhamnosus and Saccharomyces boulardii on biofilms of antibiotic resistant conditionally pathogenic and pathogenic bacteria
}

\author{
O. Y. Isayenko*, O. V. Knysh*, Y. M. Babych*, T. N. Ryzhkova**, G. I. Dyukareva*** \\ *I. I. Mechnikov Institute of Microbiology and Immunology of National Academy of Medical Sciences of Ukraine, Kharkiv, Ukraine \\ **Kharkiv State Zooveterinary Academy, Kharkiv, Ukraine \\ ***Kharkiv State University of Food Technology and Trade, Kharkiv, Ukraine
}

Article info

Received 19.02.2019

Received in revised form 22.03.2019

Accepted 25.03.2019

I. I. Mechnikov Institute of

Microbiology and Immunology of

National Academy of Medical

Sciences of Ukraine, Pushkins ka st.,

14/16, Kharkiv, 61057, Ukraine.

Tel.: +38-099-43-41-830

E-mail:el_isaenko@ukr.net

Kharkiv State Zooveterinary Academy, Akademichna st., $I$ Mala Danylivka, Dergachivsky district, Kharkiv region, 62341

Ukraine. Tel.: +38-096-38-46-058 E-mail:rujkova.ua@gmail.com

Kharkiv State University of Food

Technology and Trade,

Klochkivska st., 333,

Kharkiv, 61051, Ukraine.

Isayenko, O. Y., Knysh, O. V., Babych, Y. M., Ryzhkova, T. N., \& Dyukareva, G. I. (2019). Effect of disintegrates and metabolites of Lactobacillus rhamnosus and Saccharomyces boulardii on biofilms of antibiotic resistant conditionally pathogenic and pathogenic bacteria. Regulatory Mechanisms in Biosystems, 10(1), 3-8. doi:10.15421/021901

The work presented here is the first to examine the impact of Lactobacillus rhamnosus GG ATCC 53103 and Saccharomyces boulardii metabolites obtained using the author's method on the formation of biofilm forms of bacteria. The structural components of the probiotic microorganisms were obtained using the method of physical disintegration - low frequency ultrasound waves produced by a G3-109 generator. Metabolites were obtained by cultivating L. rhamnosus and S. boulardii in ultrasound disintegrates of lactobacteria and Saccharomycetes. The impact of biologically active substances on the formation of biofilm of Corynebacterium ulcerans tox $+112, C$. diphtheriae gravis tox +108 , by antibiotic-resistant Pseudomonas aeruginosa PR, Klebsiella pneumoniae PR, Lelliottia amnigena (Enterobacter amnigenus) PR and $P$. aeruginosa ATCC 27853 reference strain was studied using the spectrophotometric method. For the first time, we proved that L. rhamnosus GG and $S$. boulardii metabolites and combinations of metabolites of Saccharomycetes and lactobacteria, obtained by cultivating primary producers in their disintegrates, damage preformed 24-hour biofilms of gram-positive and gram-negative bacteria. The representatives of Corynebacterium exhibited higher sensitivity to the filtrates of disintegrates and products of vital activity of lactobacteria and Saccharomycetes than gram-negative pathogens. High parameters of decrease in optical density of preformed biofilms of Corynebacterium and antibiotic-resistant gram-negative bacteria were observed under the influence of combination of $L$. rhamnosus GG and $S$. boulardii metabolites (by 1.3-2.6 times). However, the largest reduction of the optical density of the formed biofilm of all studied strains was observed under the influence of metabolites of lactobacteria (by 1.5-5.3 times). Biologically active substances of L. rhamnosus GG and S. boulardii obtained using the author's method can be used as candidate preparations which could have a strong influence on the process of the formation of the biofilms and preformed biofilms, and also as a preparations of substitution/addition of therapeutic prescription.

Keywords: biofilms; toxicogenous Corynebacterium; antibiotic-resistant gram-negative microorganisms.

\section{Introduction}

Thanks to the scientific achievements of recent years, there has been great progress in understanding the complexity of the process of formation of biofilms, their importance in the development of infectious diseases of different genesis, etiological role in development of chronic diseases, and the difficulty of eliminating biofilm forms of pathogens as a result of their high resistance to antimicrobial preparations (Rybalchenko et al., 2010; Zhejun et al., 2017; Wang et al., 2018).

Biologically active components and products of peptide origin, obtained from probiotic microorganisms, have demonstrated good results due to their high antimicrobial properties (Ołdak \& Zielińska, 2017). Notable antibacterial effect against gram-positive bacteria, mostly in relation to Staphylococcus aureus, was demonstrated by LHG2 bacteriocin extracted from Lactobacillus casei. In the future, it is planned to use it for improvement of the existing antimicrobial peptides orientated against antibioticresistant pathogenic microorganisms (He et al., 2018). From Lactobacillus plantarum, bacteriocins (AMPs LR14) have been extracted with anmimycotic activity against four fungi: Aspergillus niger, Rhizopus stolonifer, Mucor racemosus and Penicillium chrysogenum (Gupta \& Srivastava, 2014). Antimicrobial substances extracted from probiotic microorganisms are promising for developing new antimicrobial preparations due to their inhibiting activity against polyresistant strains, broad range of effect, fast elimination of pathogenic bioobjects, immune-modeling effect, and low speed of induction of bacterial resistance to them (Di Luca et al., 2014; Tkachenko, 2017).

Apart from the abovementioned positive properties of biologically active substances of probiotic origin, it could be added that they have an equally strong effect on both plankton and biofilm forms of microorganisms. The impact has been reported of metabolism products of lactobacilli (Lactobacillus plantarum L3 and L. fermentum 97) on Staphylococcus aureus and $S$. epidermidis through inhibition of biofilm formation of selected cultures of bacteria (Rybalchenko et al., 2010). There have been studies on the action of nisin extracted from Lactobacillus lactis, nukacin ISK-1 and lactacin Q against biofilms of methicillin-resistant Staphylococcus (MRSA). It was determined that a combined usage of glycopeptide antibiotic vancomycin with lacticin $\mathrm{Q}$ and nisin has a bactericidal effect on MRSA biofilms in contrast to ineffective action of using vancomycin alone. Lantibiotic nukacin ISK-1 demonstrated activity only against plankton cells and did not prevent the formation of biofilms of the pathogens. Bacteriocins produced by Lactobacillus plantarum ATCC 8014 and L. acidophilus ATCC 4356 inhibit the formation 
of biofilm of Serratia marcescens. Bacteriocin extracted from Lactobacillus fermentum 97 is effective against biofilms of S. epidermidis (Mathur \& MaryRea, 2018). L. acidophilus and L. fermentum supernates are effective antimicrobial preparations against $K$. pneumoniae biofilms resistant to amikacin and gentamicin (Al-Mathkhury \& Abed Assal, 2012). It is well known that galidermin is an antibiotic of lactobacteria, which inhibits growth and formation of Staphylococcus biofilms, but does not affect the formed (24-hour) biofilm (Mathur \& MaryRea, 2018). Bacteriocin produced by Lactobacillus rhamnosus ATCC 53103 reduces the formation of biofilm of Staphylococcus aureus in rabbits after surgical change of the knee joint and its infection (Zhou \& Zhang, 2018).

Most scientific publications are focused on proving a broad range of antimicrobial effect of biologically active substances of probiotic origin on pathogenic and conditionally-pathogenic gram-positive and gram-negative microorganisms. The question of the influence of biologically active products on the processes of biofilm formation and preformed biofilms of pathogenic bacteria are described to a less extent (Rybalchenko et al., 2010; Wang et al., 2015; Frickmann et al., 2018). At the same time, preparations developed by scientists are mostly orientated against initial stages of formation of biofilms: adhesion and maturing (Di Luca et al., 2014; Wang et al., 2015). Solving this problem is much more practical because the concentration of substances needed for inhibition of the process of biofilm formation is much lower than for complete destruction of mature biofilm (Mathur \& MaryRea, 2018).

Efficient use in scientific experiments by researchers, and also our own results obtained earlier have encouraged us to study the impact of promising biologically active substances of $L$. rhamnosus GG and $S$. boulardii on the preformed biofilms of antibiotic-resistant conditionnally-pathogenic and pathogenic bacteria (Arciola et al., 2012; Isajenko et al., 2017, 2018; Osama et al., 2017; Sahib, 2017; Stefania, 2017). The objective of this study was substantiation of the opportunity of developing a candidate preparation on the basis of metabolite complexes of $L$. rhamnosus GG and $S$. boulardii, which have an effect on formed biofilms of gram-positive and gram-negative microorganisms and which would have antimicrobial activity against antibiotic-resistant pathogens.

\section{Materials and methods}

The research was performed in the Laboratory of Preventing Aerial Infections of the National Academy of Medical Sciences of Ukraine, Mechnikov Institute of Microbiology and Immunology (Kharkiv, Ukraine).

Primary producers of the disintegrates and metabolites. As a primary producers of biologically active substances, we used probiotic strains of bacteria and fungi:

1) Lactobacillus rhamnosus $\left(\mathrm{LGG}^{\circledR}\right)$ ATCC 53103 (L. rhamno-

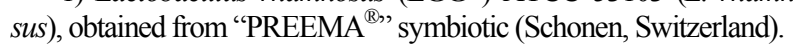

2) Saccharomyces boulardii CNCM I-745 (S. boulardii), extracted from BULARDI ${ }^{\mathbb{R}}$ preparation (Schonen, Switzerland).

Preparation of the suspensions of L. rhamnosus $G G$ and $S$. boulardii microorganisms. For obtaining biologically active substances (disintegrations and metabolites), we prepared a suspension of cells with optical density of 10.0 units according to McFarland scale with use of Densi-La-Meter device (PLIVA-Lachema Diagnostika, Czech Republic).

Obtaining of ultrasound disintegrates of L. rhamnosus GG and S. boulardii. Disintegration of cells of probiotic strains was performed by processing the suspension of microbial weighed amounts of L. rhamnosus $\mathrm{GG}(\mathrm{L})$ or $S$. boulardii (S) with low-frequency ultrasound waves produced by a GZ-109 generator, loaded on circular piezoceramic converters of ZTC type $\left(\emptyset_{\text {extemal }} \times \emptyset_{\text {intemal }} \times \mathrm{h}\right) \mathrm{mm}$. The processing was conducted in frequency range of $\Delta \mathrm{f}_{2}=35-50 \mathrm{kHz}\left(\mathrm{f}_{\max }=40.0 \mathrm{kHz}\right)$ at excitement amplitude $\mathrm{U}=15 \mathrm{~V}$ and load $\mathrm{R}=50 \Omega(\mathrm{P}=5 \mathrm{~W})$. Coefficient of conversion of electric power into acoustic equaled $\mathrm{y} \approx 5 \%$, which allowed achievement of average power of acoustic fluctuations at the position of biological object equaling $0.25-0.50 \mathrm{~W}$. Test tubes with suspensions of L. rhamnosus GG or $S$. boulardii probiotic strains were in the zone near the converter positioned in aquatic medium.

Obtaining products of metabolism of L. rhamnosus GG and S. boulardii by cultivating probiotic strains of microorganisms in ultrasound disintegrates:
1) metabolites of Lactobacillus were obtained in their own ultrasound disintegrates (structural components). For this purpose, weighed microbial amounts of L. rhamnosus GG with optical density of 10.0 units according to $\mathrm{McF}$ scale were added to the into the disintegrates of lactobacteria in $1: 9$ proportion and were cultivated at $37 \pm 1{ }^{\circ} \mathrm{C}$ for 72 hours (Sample ML) (Isajenko et al., 2017);

2) metabolites of $S$. boulardii were obtained through cultivated primary producer in their own ultrasound disintegrates (structural components) in a similar way (Sample MS);

3) for obtaining a combination of L. rhamnosus GG and S. boulardii metabolites, microbial suspensions of lactobacteria and Saccharomycetes with optical density of 10.0 units according to McF scale were added into the ultrasound disintegrates of lactobacteria in equal proportion - 1 : 1 (Sample MLS) (Isajenko et al., 2018);

4) unique metabolites (products of vital activity) of Saccharomycetes were obtained by cultivating $S$. boulardii in structural components of $L$. rhamnosus (Sample LS).

Ultrasound disintegrations and cultures, grown in the disintergrates, were centrifuged at $1100 \mathrm{~g}$ for 15 minutes, then supernatant was filtered through sterile membrane filters with pore diameter equaling $0.2 \mu \mathrm{m}$ (Vladipor, Russia).

Test-cultures, used for formation of biofilms:

1) toxicogenous Corynebacterium: C. ulcerans tox +112, C. diphtheriae gravis tox +108 ;

2) reference strain Pseudomonas aeruginosa ATCC 27853;

3) gram-negative bacteria polyresistent to antibacterial preparations: P. aeruginosa PR, Klebsiella pneumoniae PR, Lelliottia amnigena (Enterobacter amnigenus) PR, extracted from patients with inflammatory and pus-inflammatory diseases of the respiratory tract.

Some of the strains are maintained in the collection of microorganisms of the Laboratory of Preventing Aerial Infections of I. I. Mechnikov Institute of Microbiology and Immunology of National Academy of Medical Sciences of Ukraine in Kharkiv, some were obtained from the Museum of Microorganisms of I. I. Mechnikov Institute of Microbiology and Immunology in Kharkiv.

Suspensions of test-cultures of microorganisms were prepared using the McFarland scale of turbidity, using a Densi-La-Meter device (PLIVA-Lachema Diagnostika, Czech Republic). The suspension of microorganisms used in the experiment in the final solution contained $1.5 \times 10^{7} \mathrm{CFU} / \mathrm{ml}$.

Research on the influence of disintegrates and metabolites of L. rhamnosus GG and S. boulardii on the formed toxicogenous Corynebacterium and polyresistant gram-negative microorganisms of biofilm. Research on the influence of the experimental samples on the biofilms formed by the test-cultures was conducted using spectrophotometric method of Stepanović in the author's modification (Stepanović et al., 2007). The experiment consisted of initial formation of a 24-hour biofilm by microorganisms in growth medium with subsequent elimination of plankton forms of microorganisms. Then, to the formed biofilm, the studied substances of L. rhamnosus GG or S. boulardii were added; then it was maintained over 24-hours, stained and optical density of the samples was measured. This allowed us to study the impact of the produced substances on the biofilm formed by the studied culture.

Biofilms of antibiotic-resistant of gram-negative bacteria and toxicogenous strains of Corynebacterium were obtained in polystyrene 96-well microplates (EximCargoTrade, Ukraine). Into each of the wells, we added $110 \mu \mathrm{m}$ of trypticase soy broth (TSB) (HiMedia, India) with addition of $1 \%$ glucose. Into the positive control (control cultures) and experimental wells, suspensions of the test-cultures of bacteria were added, and into the negative control - isotonic solution of sodium chloride $(0.9 \%)$. The samples were incubated for 24 hours at the temperature $37 \pm 1^{\circ} \mathrm{C}$, then the content of the wells was removed, the wells were washed three times with $0.1 \mathrm{M}$ of phosphate-saline buffer (PBS, $\mathrm{pH} 7.2$ ), and $110 \mu \mathrm{m}$ of TSB with $1 \%$ glucose was added into all wells. Into the experimental wells, we added $30 \mu \mathrm{m}$ of metabolites, and into the control wells - isotonic solution of sodium chloride $(0.9 \%)$. The microplates were kept in a thermostat for 24 hours at temperature $37 \pm 1^{\circ} \mathrm{C}$. Then the content of the wells was removed, washed three times with $0.1 \mathrm{M}$ phosphate-saline buffer (PBS, pH 6.8), and the microplates were dried 
at $60 \pm 1{ }^{\circ} \mathrm{C}$ for 60 minutes. The fixated biofilms were stained with $1 \%$ solution of crystal violet, adding $150 \mu \mathrm{m} /$ well. After thorough washing with distilled water, $150 \mu \mathrm{m}$ of $96^{\circ}$ ethanol was put into each well and kept for 30 minutes at room temperature. Optical density of the samples was measured using Erba LisaScanTM EM analyzer (Germany) at wavelength of $630 \mathrm{~nm}$. Optical density of the experimental samples in relation to the control indicated presence or absence of the effect of the studied substances on the formed biofilm. Assessment of the extent of development/damage to the biofilms of control and experimental samples was performed using the formula presented by Stepanović S, and expressed in conventional units:

$$
\mathrm{OD}_{\mathrm{o}}=\mathrm{OD}_{\mathrm{c}}-\mathrm{OD}_{\mathrm{B}} \text {, }
$$

where $\mathrm{OD}_{\mathrm{B}}=\mathrm{OD}_{\text {ок }}+\left(3 \times \mathrm{SD}_{\text {ок }}\right)$, where $\mathrm{OD}_{\mathrm{o}}-$ optical density of the experimental strain, $\mathrm{OD}_{\mathrm{c}}$ - mean value of optical density of the experimental strain, $\mathrm{OD}_{\mathrm{B}}-$ value of removal, $\mathrm{OD}_{\text {ок }}-$ mean value of optical density of negative control, $\mathrm{SD}_{\text {ок }}$ - standard deviation of negative control.

Statistical analysis of the obtained results. All studies were replicated three times, in three separate experiments. The results were analyzed using Statistica 8.0 (StatSoft Inc., USA) program. We calculated mean arithmetic $(x)$ and standard error of mean arithmetic (SD). The reliability of the differences between the obtained data was determined using nonparametric Mann-Whitney U-test. Difference of experimental samples compared to the control was considered probable at values of $\mathrm{P}<0.05$.

\section{Results}

Investigation of the anti-biofilm effect of biologically active substances of L. rhamnosus GG and S. boulardii against biofilms formed by two toxicogenous strains of Corynebacterium, exhibited different degrees of reduction of their optical density (Fig. 1). Higher sensitivity to all studied substances was shown by the pathogenic strain Corynebacterium diphtheriae gravis tox +108 . The difference between all experimental samples (disintegrates and metabolites) in relation to the control samples was statistically significant $(\mathrm{P}<0.05)$ : the lowest (by 1.5 times) reduction of the optical density of the formed biofilm was following the action of the filtrate of fungal disintegrate, and the highest (by 6.1 times) damage was observed following the action of filtrate of disintegrate of lactobacteria. A statistically unreliable influence on 24-hour biofilm of this microorganism was observed following the action of metabolites of Saccharomycetes obtained by cultivating fungi on their disintegrate (MS).

Absence of reliable anti-biofilm effect against the culture of Corynebacterium ulcerans tox +112 was determined after treatment with metabolites of Saccharomycetes (MS) and disintegrates of Saccharomycetes (S) (Fig. 1). Samples which included components of lactobacteria underwent a statistically significant decrease in the parameters of experimental samples in relation to the control by $1.8-5.1$ times $(\mathrm{P}<0.05)$.

Reliable reduction of the formed biofilm of reference strain $P$. aeruginosa ATCC 27853 was observed following treatment with metabolites of lactobacteria $(\mathrm{ML})$ by 2.6 times $(\mathrm{P}<0.05)$, and with fungi metabolites obtained by cultivation of fungi on disintegrates of lactobactria (LS) by 1.9 times $(\mathrm{P}<0.05)$ (Fig. 2). Following exposure of preformed biofilm of this culture of Pseudomonas to filtrates of ultrasound disintegrates $(\mathrm{L}, \mathrm{S})$, no changes in the parameters of optical density were observed.

Biofilm developed by $P$. aeruginosa PR polyresistant strain was observed to be more sensitive to the filtrate of disintegrate of lactobacteria $(\mathrm{L})$ : reliable decrease by 1.4 times $(\mathrm{P}<0.05)$ in its optical density was observed. The impact of metabolites of L. rhamnosus GG (ML) and combination of metabolites of lactobacteria and saccharomycetes (MLS) on the biofilms of the polyresistant representative of Pseudomonas was accompanied by similar damage to 24-hour biofilms: by 1.5 times. Usage of filtrate of disintegrate of $S$. boulardii (S) led to no significant changes in optical density of preformed biofilms.

No anti-biofilm effect was demonstrated by the studied substances obtained from Saccharomycetes (S, MS, LS) and filtrate of disintegrate of lactobacteria (L) against formed by K. pneumoniae PR polyresistant strain (Fig. 3). Damage to 24-hour biofilms formed by these microorganisms was observed only after exposure to metabolites of lactobacteria, obtained by cultivating the primary producer in its disintegrate
(ML), and combination of metabolites of L. rhamnosus GG and S. boulardii (MLS). In the first case, statistically reliable reduction of optical density of biofilms by 2.3 times $(\mathrm{P}<0.05)$ was observed, and in the second - by 1.9 times $(\mathrm{P}<0.05)$.

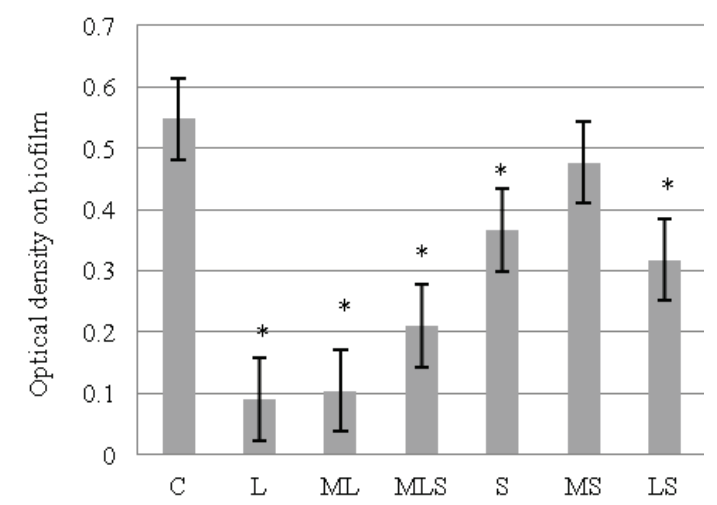

a Structural components and metabolites

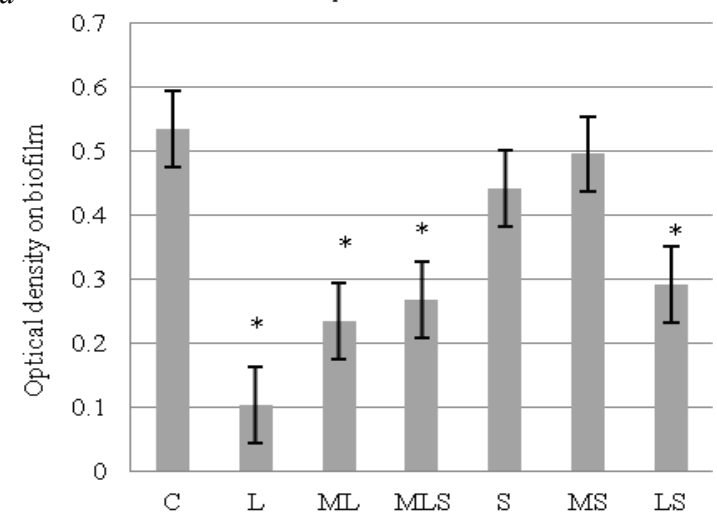

$b$

Structural components and metabolites

Fig. 1. Optical density of biofilms formed by toxicogenous strains of Corynebacterium diphtheriae gravis tox $+108(a)$ and C. ulcerans tox + 112 (b) with consequent impact on them by the filtrates of ultrasound disintegrates and metabolites of L. rhamnosus GG and S. boulardii, $\mathrm{CU}(\mathrm{x} \pm \mathrm{SD}, \mathrm{n}=3): \mathrm{K}$ - control, $\mathrm{L}$ - filtrates of disintegrates (structural components) of lactobacteria, ML - metabolites of lactobacteria,

MLS - combination of lactobacteria and Saccharomycetes, $S$ - filtrates of disintegrates (structural components) of Saccharomycetes, MS - metabolites of Saccharomycetes, obtained by cultivating saccharomycetes in their disintegrates, LS - metabolites of Saccharomycetes, obtained by cultivating Saccharomycetes in disintegrates of lactobacteria; * - difference of the experimental samples compared to the control is statistically significant $(\mathrm{P}<0.05)$

The impact of filtrates of disintegrates and metabolites of lactobacteria and Saccharomycetes on preformed biofilm of $L$. amnigena (E. amnigenus) PR polyresistant strain exhibited statistically significant reduction of optical density of all experimental samples in relation to the control (Fig. 3). The greatest effect was observed after treatment with metabolites of lactobacteria (ML): optical density of biofilms formed by the mentioned strain decreased by 2.4 times $(\mathrm{P}<0.05)$.

\section{Discussion}

There were several reasons for choosing to study the influence of the studied substances obtained from lactobacteria and Saccharomycetes on the test-cultures described in this article. Despite active vaccination being conducted against the Corynebacterium diphtheriae pathogen, outbreaks of this disease continue to be recorded around the world (WHO, 2007; MOZ, 2018). In many countries, the epidemiology of the diphtheria infection is characterized by distribution of the pathogen through bacteria-carriers. 


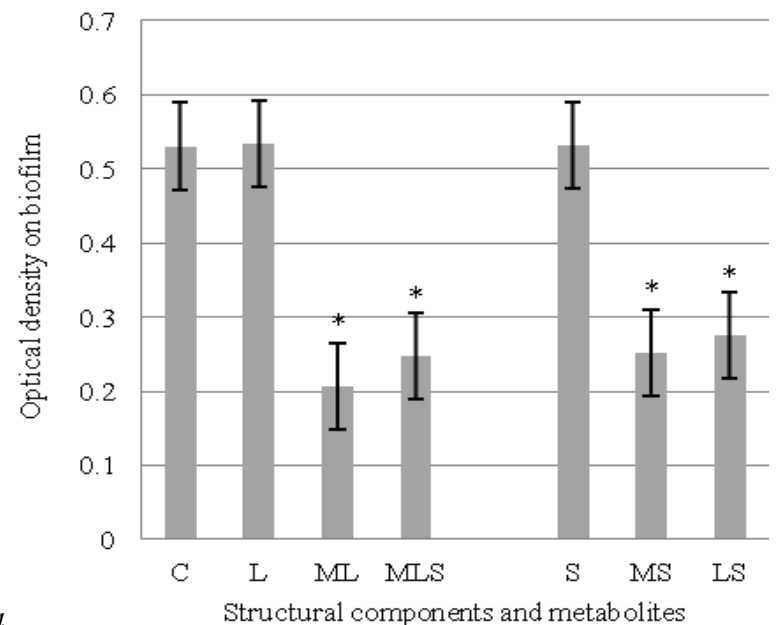

$a$

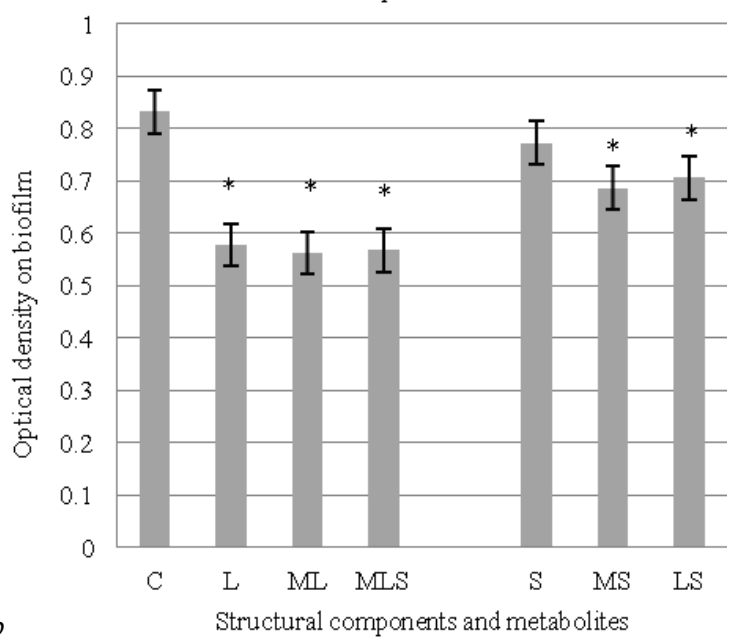

Fig. 2. Optical density of the biofilms formed by $P$. aeruginosa ATCC 27853 (a) and polyresistant strain $P$. aeruginos $\mathrm{PR}(b)$ following their treatment with filtrates of ultrasound disintegrates and metabolites of $L$.

rhamnosus $\mathrm{GG}$ and $S$. boulardii $(\mathrm{CU}, \mathrm{x} \pm \mathrm{SD}, \mathrm{n}=3$ ): see Fig. 1

Chronic respiratory diseases of a bacterial nature is a serious medicalsocial problem, affecting, according to the data of the WHO, several hundred million people (WHO, 2007). Many of these diseases have appeared as a result of formation of antibiotic-resistant microorganisms. According to the preliminary prognoses, if no efficient measures against resistant pathogens are taken, by the year 2050, 10 million people could die of infectious diseases caused by pathogen microorganisms with multiple resistance to antibiotics (Mishra et al., 2017; WHO, 2017). For this reason, we selected antibiotic-resistant gram-negative bacteria isolated from patients with inflammatory and pus-inflammatory of the respiratory tract.

One of the directions of struggle against pathogenic microorganisms is damaging their adhesion and development of biofilm. A number of authors have successfully proved the high level of antibiofilm activity of derivatives and products of vital activity obtained from probiotic strains of microorganisms, both on the processes of formation of biofilms and on preformed biofilms (Rybalchenko et al., 2010; Mathur \& Rea, 2018). Therefore, action of metabolites of Lactobacillus (L. plantarum L3 and $L$. fermentum 97) against the process of biofilm formation by $S$. aureus and $S$. epidermidis was accompanied by the death of the bacteria. Elimination of microorganisms was caused by ultrastructural changes in target cells, damaging vitally important processes (cell division, synthesis of DNA and the peptidoglycan layer) and rejection of peptidoglycan globules from the surface of cellular wall into the external medium (Rybalchenko et al., 2010). Preliminary treatment of microorganisms by cultural supernatants $L$. acidophilus HN017, L. rhamnosus DR20 or B. lactis DR10 reduces adhesion and invasion of E. coli O157: H7 (Kwannan Nantavisai, 2018).
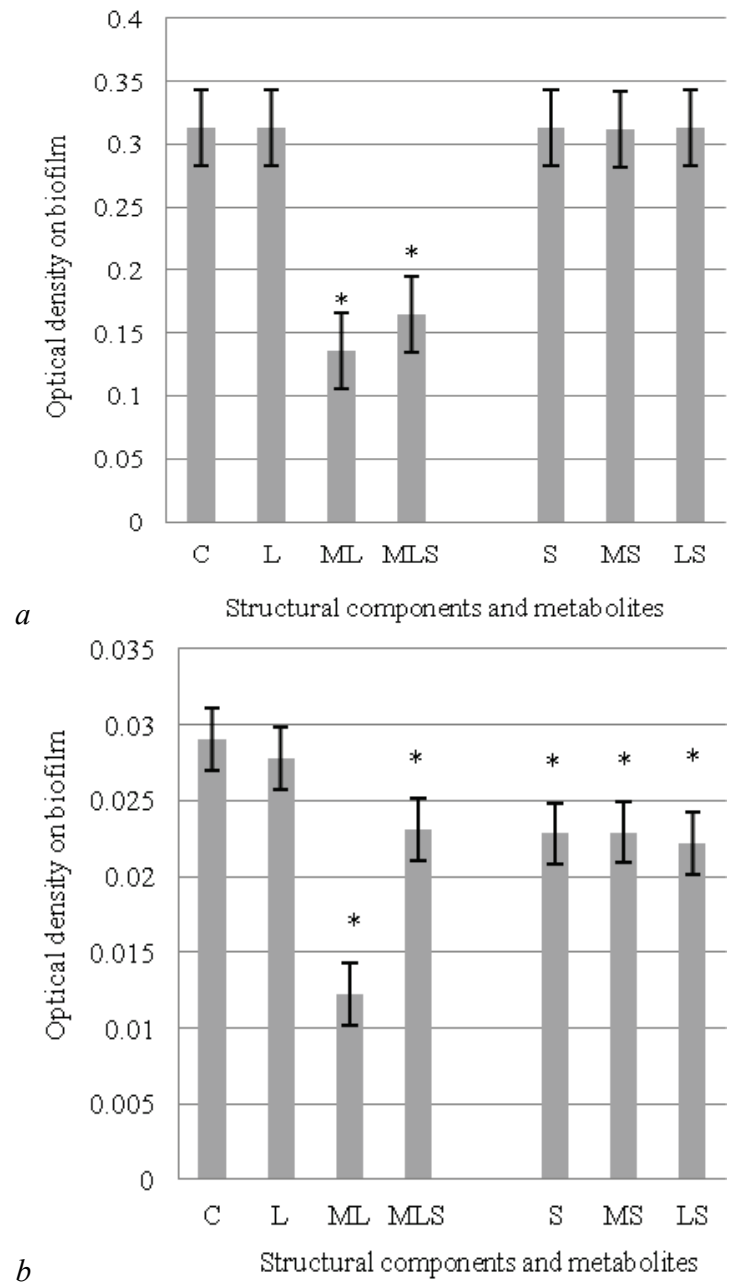

Fig. 3. Optical density of biofilms formed by polyresistant strains K. pneumoniae $\mathrm{PR}(a)$ and L. amnigena (E. amnigenus) $\mathrm{PR}(b)$ following treatment with filtrates of ultrasound disintegrates and metabolites of $L$. rhamnosus $\mathrm{GG}$ and $S$. boulardii $(\mathrm{CU}, \mathrm{x} \pm \mathrm{SD}, \mathrm{n}=3)$ : see Fig. 1

The described technology of obtaining metabolites with use of their disintegrates for cultivation of probiotic microorganisms instead of traditional nutrients was used for the first time (Isajenko et al., 2017; Isajenko et al., 2018). Such research had not been conducted before. Earlier, scientists determined the antibiofilm properties of combination of metabolites of $L$. rhamnosus GG and $S$. boulardii, obtained by cultivation of primary producers in disintegrates of lactobacteria, against formation of biofilm by antibiotic-resistant gram-negative pathogens. In some cases, higher activity was demonstrated by metabolites of lactobacteria obtained by cultivating $L$. rhamnosus in its own structural components. A more intense impact was observed on the formation of biofilms by pathogenic Corynebacterium: reduction to total inhibition of biofilms of microorganisms. The most notable effect was exhibited for use of a combination of metabolites of lactobacteria and Saccharomycetes.

Thus, the metabolites obtained using the proposed method support the literature data on the high anti-biofilm properties of products of vital activity of probiotics. It should be mentioned that study of the influence of biologically active substances of $L$. rhamnosus and $S$. boulardii on biofilm-formation of microorganisms is described in a relatively small number of works. In one of these studies, metabolites of $S$. boulardii (obtained from $1 \times 10^{8} \mathrm{CFU} / \mathrm{ml}$ of microorganisms) in the amount of 0.1 MIC showed an anti-biofilm effect on S. aureus $\left(2 \times 10^{5}\right)$ and exhibited no activity against $E$. coli (Stefania et al., 2017). Concentration of cells of probiotic strains from which the metabolites were obtained corresponded to the one selected in our experiment, and the amount of $\mathrm{CFU} / \mathrm{ml}$ of test-cultures studied by the authors was significantly lower compared to our study. 
In the study by Sahib et al. (2017), addition of silver nitrate $\left(\mathrm{AgNO}_{3}\right)$ to the microbial cells of $S$. boulardii enabled supernatant with antibacterial and antibiofilm properties to be obtained for use against the following microorganisms: S. aureus, S. pyogenes, E. coli, K. pneumoniae, E. aerogens, S. typhi, A. baumannii, $P$. auruginosa, $P$. mirabilis; its activity manifested in two concentrations of 1 and $2 \mathrm{mg} / \mathrm{ml}$.

Bacteriocins isolated by Arciola et al. (2012) from the L. rhamnosus ATCC 53103 master seed strain (cultivation in MRS broth) reduce formation of biofilm of Staphylococcus aureus ATCC 29213 (Zhou \& Zhang, 2018). The concentration of the microorganism, used in the experiment, in the final solution $\left(0.5 \times 10^{5} \mathrm{CFU} / \mathrm{ml}\right)$ was significantly lower than the amount of the test-culture bacteria we studied $\left(1.5 \times 10^{7} \mathrm{CFU} / \mathrm{ml}\right)$. Comparing the pathogens described in this article with our own studies, we should note the authors used only $S$. aureus reference strain. Though, as we know, in practical medicine the complications are caused by mostly medication-resistant microorganisms (Arciola et al., 2012).

In the next study, a group of scientists (Osama et al., 2017) studied the antibiofilm activity of metabolites of $L$. rhamnosus EMCC 1105, cultivated in MRS broth, against biofilms of circulating strains $P$. aeruginosa, S. aureus and etalon strain Escherichia coli NCTC 10959. The results the authors obtained concur well with our data and demonstrate significant reduction of biofilm of $P$. aeruginosa and $S$. aureus in presence of these substances compared to their individual biofilms. It should be mentioned that the duration of the influence of the metabolites on the microorganisms' formation of biofilm was 24 hours. The amount of pathogens' test-cultures used by the authors in the experiment $\left(2 \times 10^{5} \mathrm{CFU} / \mathrm{ml}\right)$ was significantly lower compared to the amount we studied $\left(1.5 \times 10^{7} \mathrm{CFU} / \mathrm{ml}\right)$. However, the significantly higher concentration of microbial cells of the tested microorganisms did not prevent the achievement of a high anti-biofilm effect of the metabolites obtained by cultivating primary producers in their disintegrates.

In this study, the impact of metabolites of L. rhamnosus and S. boulardii obtained using the authors' method on developed biofilm forms of pathogens was investigated for the first time. The results we obtained prove and supplement the literature data. In the studies by Karthik Sambanthamoorthy (2014), it was determined that metabolites of L. rhamnosus exhibit activity against formation of biofilm of A. baumannii, E. coli and $S$. aureus. Under their influence, in $25-50 \mathrm{mg} / \mathrm{ml}$ concentrations, using electronic microscopy, damage to the membrane of A. baumannii and cellular wall of $S$. aureus was proved. Also, the effect was determined of the studied substances of L. rhamnosus on biofilms formed earlier by these microorganisms at duration of impact of $\sim 18 \mathrm{~h}$; no effect was observed for 1 hour's exposure. The data obtained by the authors concur with our results, which demonstrated reduction of optical density of preformed biofilms of antibiotic-resistant gram-negative bacteria and toxicogenous strains of Corynebacterium after 24 hours (interval of monitoring).

Biologically active substances of $L$. rhamnosus GG and $S$. boulardii obtained using the authors' method can be used as candidate preparations which can actively affect the process of formation of biofilms and preformed biofilms, and also be used as additional preparations of therapeutic purpose.

\section{Conclusions}

The most notable reduction of 24-hour biofilms was observed for the impact of metabolites of lactobacteria (ML), which was characterized by reduction of optical density by $1.5-5.3$ times $(\mathrm{P}<0.05)$ regardless of the species of the studied test-cultures. Despite the high level of antimicrobial activity of the combination of metabolites of lactobacteria and Saccharomycetes (MLS) in relation to pathogenic Corynebacterium, the antibiofilm activity was lower compared to metabolites of lactobacteria (ML). Accordingly, optical density of prebiofilms of all the studied microorganisms statistically reliably decreased by 1.3 2.6 times $(\mathrm{P}<0.05)$ under the influence of a mixture of metabolites of L. rhamnosus GG and S. boulardii (MLS). Treatment of pre-formed biofilms with filtrates of disintegrates of lactobacteria (L) and metabolites of fungi (MS) demonstrated less notable antibiofilm effect, which depended on individual sensitivity of the studied test-strain to the studied substances of $L$. rhamnosus GG and $S$. boulardii. Anti-biofilm activity of filtrates of disintegrates of $S$. boulardii (S) manifested only against the toxicogenous representative Corynebacterium diphtheriae gravis tox +108 and L. amnigena (E. amnigenus) PR, optical density of their biofilms decreasing by 1.5 times $(\mathrm{P}<0.05)$ and by 1.3 times respecttively $(\mathrm{P}<0.05)$.

\section{References}

Al-Mathkhury, H. J. F., \& Abed Assal, S. D. (2012). Inhibitory effect of lactobacilli filtrate on Klebsiella pneumoniae biofilm. The Iraqi Postgraduate Medical Journal, 11(2), 169-181.

Arciola, C. R., Campoccia, D., Speziale, P., Montanaro, L., \& Costerton, J. W. (2012). Biofilm formation in Staphylococcus implant infections. A review of molecular mechanisms and implications for biofilm-resistant materials. Biomaterials, 33(26), 5967-5982.

Bousquet, J., \& Khaltaev, N. (2007). Global surveillance, prevention and control of chronic respiratory diseases: A comprehensive approach. World Health Organization, Geneva, Switzerland.

De Marco, S., Piccioni, M., Muradyan, D., Zadra, C., Pagiotti, R., \& Pietrella, D. (2017). Antibiofilm and antiadhesive activities of different synbiotics. Journal of Probiotics and Health, 5, 182.

Di Luca, M., Maccari, G., \& Nifosì, R. (2014). Treatment of microbial biofilms in the post-antibiotic era: Prophylactic and therapeutic use of antimicrobial peptides and their design by bioinformatics tools. Pathogens and Disease, 70(3), 257-270.

Dzhoraeva, S. K., Goncharenko, V. V., Shchegoleva, E. V., Shcherbakova, J. V., \& Bezruchenko, A. A. (2015). Sostav i funktcii mikrobiotcenozov razlichnykh biotopov makroorganizma i klinicheskaia znachimost ikh narushenii [Composition and functions of microbiocenoses of different biotopes of the macroorganism and clinical significance of their disorders dermatology and venerology]. Dermatologiia ta Venerologiia, 68(2), 5-19 (in Russian).

Frickmann, H., Warnke, P., Klenk, C., \& Redanz, S. (2018). Influence of probiotic culture supernatants on in vitro biofilm formation of staphylococci. European Journal of Microbiology and Immunology, 8(4), 119-127.

Gabrielyan, N. I., Gorskaya, E. M., Romanova, N. I., \& Tsirulnikova, O. M. (2012). Gospital'naja mikroflora i bioplenki [Nosocomial infection and microbial biofilms in surgery]. Russian Journal of Transplantology and Artificial Organs, 14(3), 83-91 (in Russian).

Golub, A. V. (2012). Bakterialnye bioplenki - novaia cel' terapii? [Bacterial biofilms - A new therapeutic target?]. Clinical Microbiology and Antimicrobial Chemotherapy, 14(1), 23-30 (in Russian).

Gupta, R., \& Srivastava, S. (2014). Antifungal effect of antimicrobial peptides (AMPs LR14) derived from Lactobacillus plantarum strain LR/14 and their applications in prevention of grain spoilage. Food Microbiology, 42, 1-7.

Haney, E. F., Trimble, M. J., Cheng J. T., Vallé, Q., \& Hancock, R. W. (2018). Critical assessment of methods to quantify biofilm growth and evaluate antibiofilm activity of host defence peptides. Biomolecules, 8(2), 29.

He, J., Luo, X., Jin, D., Wang, Y., \& Zhang, T. (2018). Identification, recombinant expression, and characterization of LHG2, a novel antimicrobial peptide of Lactobacillus casei HZ1. Molecules, 23(9), 2246.

Lagun, L. V., \& Zhavoronok, S. V. (2013). Bakterialnye bioplenki i ikh rol v razvitii infektcii mochevyvodiashchikh putei [Bacterial biofilms and their role in the development of urinary tract infections]. Meditcinskii Zhurnal, 4, 21-27 (in Russian).

Mathur, H., Rea, M. C., Field, D., \& Ross, R. P. (2018). Fighting biofilms with lantibiotics and other groups of bacteriocins. Biofilms and Microbiomes, 4(9), 2-13.

Mishra, B., Reiling, S., Zarena, D., \& Wang, G. (2017). Host defense antimicrobial peptides as antibiotics: Design and application strategies. Current Opinion in Chemical Biology, 38, 87-96.

Nantavisai, K, Puttikamonkul, S., Chotelersak, K., \& Taweechotipatr, M. (2018). In vitro adhesion property and competition against enteropathogens of Lactobacillus strains isolated from Thai infants. Songklanakarin Journal of Science and Technology, 40(1), 69-74.

Ołdak, A., \& Zielińska, D. (2017). Bacteriocins from lactic acid bacteria as an alternative to antibiotics. Postepy Postępy Higieny i Medycyny Doświadczalnej, 71(1), 328-338.

Osama, D. M., Elkhatib, W. F., Tawfeik, A. M., Aboulwafa, M. M., \& Hassouna, N. A.-H. (2017). Antimicrobial, antibiofilm and immunomodulatory activities of Lactobacillus rhamnosus and Lactobacillus gasseri against some bacterial pathogens. International Journal of Biotechnology for Wellness Industries, 6(1), 12-21.

Rybalchenko, O. V., Bondarenko, V. M., \& Orlova, O. G. (2014). Ultrastruktura bioplenok pri vnutrividovom i mezhvidovym vzaimodeistvii uslovno patogennykh bakterij [Ultrastructure of biofilms with intraspecific and interspecific 
interactions of conditionally pathogenic bacteria]. Bjulleten' Orenburgskogo Nauchnogo Centra, 1, 1-11 (in Russian).

Rybalchenko, O. V., Bondarenko, V. M., Orlova, O. G., Larionov, I. V., \& Fialkina, S. V. (2010). Dezorganizatciia bioplenok klinicheskikh shtammov stafilokokkov metabolitami laktobatcill [Disorganization of biofilms of clinical staphylococcal strains by lactobacillus metabolites]. Zhurnal Mikrobiologii, Epidemiologii i Immunobiologii, 6, 66-70 (in Russian)

Sahib, F. H., Aldujaili, N. H., \& Alrufae, M. M. (2017). Biosynthesis of silver nanoparticles using saccharomyces boulardii and study their biological activities. European Journal of Pharmaceutical and Medical Research, 4(9), 65-74.

Shaikh, A. M., \& Sreeja, V. (2017). Metabiotics and their health benefits. International Journal of Fermented Foods, 6(1), 11-23.

Stepanović, S., Vuković, D., Hola, V., Bonaventura, G., Djukić, S., Ćirković, I., \& Ruzicka, F. (2007). Quantification of biofilm in microtiter plates: Overview of testing conditions and practical recommendations for assessment of biofilm production by staphylococci. APMIS, 115(8), 891-899.

Tkachenko, T. (2017). Smogut li antimikrobnye peptidy zamenit antibiotiki? [Will antimicrobial peptides be able to replace antibiotics?]. Farmatcevt Praktik, 3 16-18 (in Russian).
Urgent need for new antibiotics to tackle antimicrobial resistance, says WHO (2017). The Pharmaceutical Journal, 299; 7905.

Wang, D., Haapasalo, M., Gao, Y., Ma, J., \& Shen, Y. (2018). Antibiofilm peptides against biofilms on titanium and hydroxyapatite surfaces. Bioactive Materials, 3(4), 418-425

Wang, D., Shen, Y., Hancock, R. E. W., Ma, J., \& Haapasalo, M. (2018). Antimicrobial effect of peptide djk-5 used alone or mixed with edta on mono- and multispecies biofilms in dentin canals. Journal of Endodontics, 44(11), 1709-1713.

Wang, H. Y., Cheng, J. W., Yu, H. Y., Lin, L., Chih, Y. H., \& Pan, Y. P. (2015). Efficacy of a novel antimicrobial peptide against periodontal pathogens in both planktonic and polymicrobial biofilm states. Acta Biomaterialia, 25, 150-161.

Wang, Z., Shen, Y., \& Haapasalo, M. (2017). Antibiofilm peptides against oral biofilms. Journal of Oral Microbiology, 9(1), 1327308.

Zhou, B., \& Zhang, D. (2018). Antibacterial effects of bacteriocins isolated from Lactobacillus rhamnosus (ATCC 53103) in a rabbit model of knee implant infection. Experimental and therapeutic medicine, 15(3), 2985-2989. 